\title{
Urogenital chlamydiosis among Slovak women
}

\author{
Mikulova $\mathrm{J}^{1}$, Halanova $\mathrm{M}^{2}$, Cislakova $\mathrm{L}^{2}$, Pohorencova $\mathrm{A}^{2}$, Szovenyiova $\mathrm{Z}^{3}$, Fandakova $\mathrm{I}^{3}$, \\ Huljakova $\mathrm{M}^{1}$, Klein $\mathrm{D}^{4}$, Valko $\mathrm{J}^{2}$, Jarcuska $\mathrm{P}^{2}$
}

2nd Clinic of Gynaecology and Obstetrics, University Hospital Kosice, Slovakia. monika.halanova@upjs.sk

\begin{abstract}
Objective: To investigate the prevalence of urogenital chlamydial infections in women from Eastern Slovakia and to compare the occurrence in women with and without clinical signs of disease.

Material and methods: We examined a total of 1978 women from Eastern Slovakia for the presence of C. trachomatis over a three year period. Antichlamydial antibodies of classes IgG and IgA were detected by ELISA while PCR was applied to detect pathogen.

Results: $3.6 \%$ of the population had presence of antibodies while $10.1 \%$ of the women showed presence of bacteria by PCR.

Conclusions: Obtained results when compared with clinical examination revealed clear distinction, which was age dependent. Lower age categories were more likely affected by acute infection with positivity for IgA and IgG antibodies as well as PCR. Middle age categories showed significantly higher level of IgG antibodies in comparison to $\operatorname{IgA}$, while pathogen was readily detected by PCR. In women older than 51 years the results reflected more likely a past infection that is presence of only IgG and negative PCR (Tab. 4, Ref. 18). Full Text in PDF www.elis.sk.

Key words: urogenital chlamydiosis, women, incidence, age, diagnosis.
\end{abstract}

According to WHO estimate more than 340 million new cases of curable, sexually transmitted infections, namely those due to Treponema pallidum, Neissseria gonorrhoeae, Chlamydia trachomatis, and Trichomonas vaginalis, occur throughout the world every year in men and women aged 15-49 years (1). From this number about 92 million infections are caused by Chlamydia trachomatis with the largest proportion in developing countries. Population-based studies in Europe and USA suggested that the prevalence of Chlamydia in men and women between 15-24 years of age is $2-6 \%(2,3,4,5)$. The peak age group for infection is $16-19$ years in women and 20-24 years in men (6). Generally, comparison of the prevalence of Chlamydia trachomatis infections across countries is complicated because most of the countries do not have legalised reporting of urogenital chlamydial infections and in those who have done so, the quality of the reporting system is poor (7). The comparison is also complicated due to the different diagnostic methods and sample selection techniques applied (8).

In Slovakia, there is no specific law establishing systematic screening of this infection and the disease is not included in the

12nd Clinic of Gynaecology and Obstetrics, University Hospital Kosice, Slovakia, ${ }^{2}$ Faculty of Medicine, PJ. Safarik University, Kosice, Slovakia, ${ }^{3} \mathrm{AVILAB}$ - microbiological laboratory, Kosice, Slovakia, and ${ }^{4}$ Faculty of Science, PJ Safarik University, Kosice, Slovakia

Address for correspondence: M. Halanova, MD, PhD, Department of Public Health, PJ Safarik University, Faculty of Medicine, Srobarova 2, SK-041 80 Kosice, Slovakia.

Phone: +421.55.2343374, Fax:+421.55.6420253

Acknowledgement: This study was supported by the Slovak Grant Committee VEGA MS SR, Grant No. 1/0418/09. We thank Dr. Mangesh Bhide, $\mathrm{PhD}$. for review of scientific English language. category of notifiable diseases. Therefore the data about prevalence of urogenital chlamydial infections differ significantly depending mainly on the diagnostic method used.

The aim of our study was to investigate the prevalence of urogenital chlamydial infection in women from Eastern Slovakia and to compare the occurrence in women with and without clinical signs of disease.

\section{Material and methods}

\section{Study population}

A total of 1978 women were examined for the presence of bacterium $C$. trachomatis during the years 2006-2008 in the Department of Gyneacology and Obstetrics of Faculty of Medicine of PJ Safarik University, and Gyncentrum, Ltd., Kosice.

Based on the clinical symptoms women were grouped as follows: 448 women with recurrent colpitis (RC), 517 women with cervicitis (C), 228 with salpingitis (S), 317 with another inflammatory disease of the urogenital tract (AID), 71 women with dysmenorrhoea and pelvic pain (DPP), 141 pregnant women (P) and 106 women with primary or secondary sterility (STER). Women showing no pathological symptoms (150) at routine gynaecological examination served as a control (CG).

Patients were also divided into 6 groups according to their age: $15-20$ years $(n=158), 21-25$ years $(n=339), 26-30$ years $(n=362), 31-40$ years $(n=491), 41-50$ years $(n=353)$ and older than 51 years $(n=275)$.

\section{Collection of samples}

Aspection of the external genitals of the patients was followed by a sterile speculum exam. After evaluation of the character of 
Tab. 1. Incidence of $\boldsymbol{C}$. trachomatis infection in relation to age structure of examined women.

\begin{tabular}{|c|c|c|c|c|c|c|c|}
\hline \multirow[t]{3}{*}{ Age category } & \multirow{3}{*}{$\mathrm{n}$} & \multicolumn{6}{|c|}{ Diagnostic method } \\
\hline & & \multicolumn{2}{|c|}{$\operatorname{Ig} \mathrm{A}$} & \multicolumn{2}{|c|}{$\operatorname{IgG}$} & \multicolumn{2}{|c|}{ PCR } \\
\hline & & $\mathrm{p}$ & $\%$ & $\mathrm{p}$ & $\%$ & $\mathrm{p}$ & $\%$ \\
\hline $15-20$ & 158 & 7 & 4.4 & 7 & 4.4 & 7 & 4.4 \\
\hline $21-25$ & 339 & 12 & 3.5 & 23 & 6.8 & 15 & 4.4 \\
\hline $26-30$ & 362 & 17 & 4.7 & 28 & 7.7 & 18 & 5 \\
\hline $31-40$ & 491 & 28 & 5.7 & 59 & 12 & 19 & 3.9 \\
\hline $41-50$ & 353 & 21 & 5.9 & 43 & 12.2 & 9 & 2.5 \\
\hline$\geq 51$ & 275 & 20 & 7.3 & 40 & 14.5 & 4 & 1.5 \\
\hline $\bar{\Sigma}$ & 1978 & 105 & 5.3 & 200 & 10.1 & 72 & 3.6 \\
\hline
\end{tabular}

Tab. 2. Incidence of $C$. trachomatis infection in relation to diagnosis made of examined women.

\begin{tabular}{|c|c|c|c|c|c|c|c|}
\hline \multirow[t]{3}{*}{ Diagnosis made } & \multirow{3}{*}{$\mathrm{n}$} & \multicolumn{6}{|c|}{ Diagnostic method } \\
\hline & & \multicolumn{2}{|c|}{$\operatorname{IgA}$} & \multicolumn{2}{|c|}{$\operatorname{IgG}$} & \multicolumn{2}{|c|}{ PCR } \\
\hline & & $\mathrm{p}$ & $\%$ & $\mathrm{p}$ & $\%$ & $\mathrm{p}$ & $\%$ \\
\hline$\overline{\mathrm{RC}}$ & 448 & 31 & 6.9 & 51 & 11.4 & 15 & 3.3 \\
\hline $\mathrm{C}$ & 517 & 28 & 5.4 & 52 & 10.1 & 26 & 5.0 \\
\hline $\mathrm{S}$ & 228 & 7 & 3.1 & 15 & 6.6 & 5 & 2.2 \\
\hline AID & 317 & 13 & 4.1 & 22 & 6.9 & 10 & 3.1 \\
\hline DPP & 71 & 17 & 23.9 & 33 & 46.5 & 2 & 2.8 \\
\hline STER & 106 & 4 & 3.8 & 16 & 15.1 & 6 & 5.7 \\
\hline $\mathrm{P}$ & 141 & 2 & 1.4 & 3 & 2.1 & 3 & 2.1 \\
\hline $\mathrm{CG}$ & 150 & 3 & 2 & 8 & 5.3 & 5 & 3.3 \\
\hline $\bar{\sum}$ & 1978 & 105 & 5.3 & 200 & 10.1 & 72 & 3.6 \\
\hline
\end{tabular}

Tab. 3. Significant differences between positive cases in individual age categories.

\begin{tabular}{|c|c|c|c|c|c|c|}
\hline \multirow{3}{*}{ Age category } & \multicolumn{6}{|c|}{ Diagnostic method } \\
\hline & \multicolumn{2}{|c|}{$\operatorname{Ig} \mathrm{A}$} & \multicolumn{2}{|c|}{$\mathrm{IgG}$} & \multicolumn{2}{|c|}{ PCR } \\
\hline & OR & $95 \% \mathrm{CI}$ & OR & $95 \% \mathrm{CI}$ & OR & $95 \% \mathrm{CI}$ \\
\hline $15-20$ & 1.00 & & 1.00 & & 1.00 & \\
\hline $21-25$ & 0.79 & $0.31-2.05$ & 1.57 & $0.659-3.74$ & 0.99 & $0.4-2.5$ \\
\hline $26-30$ & 1.06 & $0.43-2.61$ & 1.8 & $0.77-4.23$ & 1.13 & $0.46-2.76$ \\
\hline $31-40$ & 1.31 & $0.56-3.05$ & $2.95 * *$ & $1.32-6.6$ & 0.87 & $0.36-2.11$ \\
\hline $41-50$ & 1.36 & $0.57-3.28$ & $2.992 * *$ & $1.31-6.8$ & 0.67 & $0.21-1.54$ \\
\hline$\geq 51$ & 1.69 & $0.69-4.1$ & $3.67 * *$ & $1.6-8.41$ & 0.32 & $0.09-1.11$ \\
\hline
\end{tabular}

$* \mathrm{p} \leq 0.05 ; * * \mathrm{p} \leq 0.01 ; * * * \mathrm{p} \leq 0.001(2$-tailed)

vaginal secretion and removal of cervical plug with a sterile cotton ball, an endocervical specimen was taken by a standard procedure using a Dacron swab. The specimen was transported in AMPLICOR Specimen Transport Medium (STM) for examination by PCR. At the same time a blood sample was taken from vena cubiti of each patient for serological examination for anti-chlamydial antibodies by indirect ELISA.

\section{Laboratory methods}

The disease was diagnosed by two different methods. Antichlamydial antibodies of classes IgG and IgA were detected by serological method ELISA using commercial kits Anti-Chlamydia trachomatis ELISA IgA and Anti-Chlamydia trachomatis ELISA IgG (EUROIMMUN). A direct proof of the pathogen was obtained by polymerase chain reaction (PCR) by means of a commercial kit Amplicor CT/NG (Roche).

\section{Statistical methods}

Results were evaluated by descriptive statistics, contingence tables, correlation analysis - correlation $\varphi$ coefficient for deter- mination of closeness of the relationship between two nominal variables, Fisher's exact test or $\chi$-square test for determination of differences in the occurrence of selected characters, GoodmanKruskal gamma for determination of measures of agreement. In all the tests $\alpha<0.05$ was considered the level of significance. For women in the study sample the effects of age and diagnosis made on the presence of $C$. trachomatis were explored using logistic regression separately for each of three methods of determination.

\section{Results}

Results obtained were evaluated statistically for two variable dependents. The first, age dependent structure of the infection and presence of antibodies; and the second, clinical symptoms with diagnostic method used.

\section{Determination of IgA anti-chlamydial antibodies}

Of the total number of 1978 women included in the study the presence of anti-chlamydial IgA antibodies was recorded in 105 cases $(5.3 \%)$. These results were evaluated in relation to age factor 
Tab. 4. Significant difference between positive cases in clinical diagnosis made.

\begin{tabular}{|c|c|c|c|c|c|c|}
\hline \multirow[t]{3}{*}{ Diagnosis made } & \multicolumn{6}{|c|}{ Diagnostic method } \\
\hline & \multicolumn{2}{|c|}{$\operatorname{Ig} \mathrm{A}$} & \multicolumn{2}{|c|}{$\mathrm{IgG}$} & \multicolumn{2}{|c|}{ PCR } \\
\hline & OR & $95 \% \mathrm{CI}$ & OR & $95 \% \mathrm{CI}$ & OR & $95 \% \mathrm{CI}$ \\
\hline $\mathrm{RC}$ & $3.64 *$ & $1.09-12.09$ & $2.28 *$ & $1.06-4.92$ & 1.01 & $0.36-2.81$ \\
\hline $\mathrm{C}$ & 2.81 & $0.84-9.36$ & 1.99 & $0.92-4.28$ & 1.54 & $0.58-4.07$ \\
\hline $\mathrm{S}$ & 1.55 & $0.39-6.1$ & 1.25 & $0.52-3.03$ & 0.65 & $0.19-2.29$ \\
\hline AID & 2.1 & $0.59-7.47$ & 1.32 & $0.58-5.05$ & 0.95 & $0.32-2.81$ \\
\hline DPP & $15.43 * * *$ & $4.35-54.73$ & $15.41 * * *$ & $6.58-36.11$ & 0.84 & $0.16-4.44$ \\
\hline STER & 1.92 & $0.42-8.77$ & $3.16^{*}$ & $1.29-7.68$ & 1.74 & $0.52-5.86$ \\
\hline $\mathrm{P}$ & 0.71 & $0.12-4.28$ & 0.39 & $0.1-1.49$ & 0.63 & $0.15-2.69$ \\
\hline $\mathrm{CG}$ & 1.00 & & 1.00 & & 1.00 & \\
\hline
\end{tabular}

${ }^{*} \mathrm{p} \leq 0.05 ; * * \mathrm{p} \leq 0.01 ; * * * \mathrm{p} \leq 0.001$ (2-tailed)

(Tab. 1) and the diagnostic method used (Tab. 2). No significant difference between positive cases in individual age categories was observed (Tab. 3).

We observed the highest occurrence of IgA antibodies in the patients with dysmenorrhoea or pelvic pain. Significantly more women in this group were positive for presence of $\operatorname{IgA}$ than in the control group (OR: 15.43; 95\% CI: 4.35-54.73). Statistically significant result was also observed in the group with recurrent colpitis compared to control group (OR: 3.64 ; 95\% CI: 1.09 12.09) (Tab. 4).

\section{Determination of $\operatorname{Ig} G$ anti-chlamydial antibodies}

Of the total 1978 women included in the study the presence of IgG antichlamydial antibodies was recorded in 200 cases $(10.1 \%)$ (Tabs 1,2). The results obtained had a similar trend to that observed in IgA detection (Tab. 4). Women with dysmenorrhoea showed presence of significantly higher percentage of anti-chlamydial IgG antibodies than in control group (OR: 15.41; 95\% CI: 6.58-36.11). Significant differences in the positivity for anti-chlamydial IgG antibodies were also observed between women with primary or secondary sterility (OR: 3.16; 95\% CI: 1.29-7.68) and with recurrent colpitis (OR: 2.28; 95\% CI: 1.06-4.92) (Tab. 4).

Statistical evaluation showed significant differences between positivity among age categories. Statistically significant results were observed in the group of women older than 31 year compared to teenager girls (Tab. 3). PCR revealed presence of bacteria in 72 cases, which corresponded to $3.6 \%$ (Tabs 1,2). Results obtained were evaluated in relation to age (Tab. 3) and diagnostic test used (Tab. 4). Lower age categories were more likely affected by acute infection with positivity for IgA and IgG antibodies as well as PCR. Middle age categories showed significantly higher level of $\mathrm{IgG}$ antibodies in comparison to $\operatorname{IgA}$, while pathogen was readily detected by PCR. In women older than 51 years the results reflected more likely a past infection that is presence of only IgG and PCR negative.

\section{Discussion}

An urogenital chlamydial infection is not only serious from medical but also from social point of view, because of the high morbidity with frequent complications involving infertility in both sexes. In addition, the infection may result in intrauterine infection of the foetus and eventually causes premature birth, infection of newborns manifested by occurrence of pneumonia and conjunctivitis.

Results obtained by ELISA together with clinical examination and direct detection of pathogen by PCR indicate that lower age categories, i.e. 15-30 years old women, were more likely affected by acute infection, that is positive for both $\operatorname{IgA}$ and $\operatorname{IgG}$ antibodies as well as positive for the presence of bacteria in PCR analysis (4.2 $\%$ vs $6.7 \%$ vs $4.7 \%$ ). Middle age categories ( $31-50$ years) showed significantly higher level of IgG antibodies in comparison with IgA antibodies (12\% vs $5.8 \%$ ) and only $3.3 \%$ positivity detected by PCR method. Such results are observed more frequently in patients with chronic infections, while in patients who had overcome an acute infection, the absence of $\operatorname{IgA}$ and IgM antibodies and negative PCR results is a common picture. In women older than 51 years of age, results reflected a past infection. These considerations are confirmed by the fact that in the latter group of women we observed a significant difference in the positivity for antibodies of classes $\operatorname{IgA}$ and $\operatorname{IgG}(7.3 \%$ vs $14.5 \%)$ and direct detection of the agent by the PCR method showed only $1.5 \%$ positivity. Results obtained in our study agree with those obtained in other countries which indicated that $C$. trachomatis infection occurred more frequently in young, sexually active women, particularly in adolescents $(9,10,11,12)$.

Although our study showed very low C. trachomatis positivity in the control group (without any symptoms), one must keep a fact in mind that symptom-free course of chlamydial infection represens a threat of spreading the infection to their sexual partners or they may transfer the infection to new born. About two third of the babies may acquire infection that is usually manifested by conjunctivitis (13). About 10-20\% of exposed babies develop chlamydial pneumonia that may be associated with pulmonary diseases like asthma or bronchitis at a later age (14).

Because the majority of patients with urogenital chlamydial infection are asymptomatic, they most likely do not seek medical help. The abrupt increase in the incidence of this infection observed in the past decade, not only in Europe but throughout the world, indicates the necessity to focus particularly on prevention and screening programmes.

With regard to the striking dependence of prevalence of chlamydial infections on age, the majority of recommendations derive from age structure of examined individuals. Screening ex- 
amination should be carried out once a year at routine examination of sexually active women 25 years old and younger and in asymptomatic women from risk groups (Roma population, drug users, prostitutes, patients with other sexually transmissible diseases). It is also recommended to test pregnant women in the first trimester of gestation (15). Evidence was provided as to the correlation between $C$. trachomatis infection and premature uterine activity with subsequent significantly higher perinatal mortality in pregnant women positive for $C$. trachomatis $(16,17,18)$.

Effectiveness of screening for $C$. trachomatis depends to a considerable degree on the diagnostic method used. Despite the fact that the tests based on amplification of nucleic acids are considered presently an ideal diagnostic method, they are not cost effective.

Despite seriousness and severe consequences of this infection no specific law has been established for surveillance of urogenital chlamydial infection. There are no obligations to report this disease to the central epidemiological information system in the Slovak Republic. One of the basic principles that should be applied in practice is the change of orientation of the existing health system from the present treatment-oriented system to preventionoriented one with preference for preventive measures focused on large population groups.

\section{References}

1. WHO. Global Strategy for the Prevention and Control of Sexually Transmitted Infections: 2006-2015. Geneva: WHO 2007; 1-61.

2. Andersen B, Olesen F, Moller JK, Ostergaard L. Population-based strategies for outreach screening of urogenital Chlamydia trachomatis infections: a randomized, controlled trial. J Infect Dis 2002; 185; 252-258.

3. Fenton KA, Duncan B, Hart GJ. Chlamydia screening and sexual health: are we failing heterosexual men? Sex Transm Infect 2002; 78; 396-397.

4. Miller WC, Ford CA, Morris M, Handcock MS, Schmitz JL, Hobbs MM, Cohen MS, Harris KM, Udry JR. Prevalence of chlamydial and gonococcal infections among young adults in the United States. JAMA 2004; 291; 2229-2236.

5. Van Bergen J, Götz HM, Richardus JH, Hoebe C, Broer J, Coenen A. Prevalence of urogenital Chlamydia trachomatis increases significantly with level of urbanisation and suggests targeted screening approaches: results from the first national population based study in the Netherlands. Sex Transm Infect 2005; 81; 17-23.

6. UK Collaborative Group for HIV and STI Surveillance. Testing Times - HIV and Other Sexually Transmitted Infections in the UK: 2005. London: Health Protection Agency, Centre for Infections.
7. Domeika M, Hallén A, Karabanov L, Chudomirova K, Gruber F, Unzeitig V, Pöder A, Deak J, Jakobsone I, Lapinskaite G, Dajek Z, Akovbian V, Gomberg M, Khryanin A, Savitcheva A, Takac I, Glazkova L, Vinograd N, Nedeljkovic M et al. Chlamydia trachomatis infections in Eastern Europe: legal aspects, epidemiology, diagnosis, and treatment. Sex Transm Infect 2002; 78; 115-119.

8. Kučinskiené V, Šutaité I, Valiukevičiené S, Milašauskiené Ž, Domeika M. Prevalence and risk factors of genital Chlamydia trachomatis infection. Medicina (Kaunas) 2006; 11; 885-894.

9. Svensson LO, Mares I, Mardh PA, Olsson PE. Screening voided urine for Chlamydia trachomatis in asymptomatic adolescent females. Acta Obstet Gynecol Scand 1994; 73; 63-66.

10. Tchoudomirova K, Nuhova P, Tchapanova A. Prevalence, epidemiological and clinical correlates of genital Chlamydia trachomatis infection. J Eur Acad Dermatol Venerol 1998; 11; 214-220.

11. Munk C, Morris CA, Kjaer SK, Poll PA, Bock JE, Meijer CJ, van den Brule AJ. PCR-detected Chlamydia trachomatis infections from the uterine cervix of young women from the general population: prevalence and risk determinants. Sex Transm Dis 1999; 26; 325-328.

12. Wilson JS, Honey E, Templeton A, Paavonen J, Mårdh PA, Stray-Pedersen B, EU Biomed Concerted Action Group. A systematic review of the prevalence of Chlamydia trachomatis among European women. Hum Reprod Upd 2002; 4; 385-394.

13. Šimko J. Chlamýdiové infekcie z pohl’adu gynekológa. Via Pract 2005; $4 ; 204-205$.

14. Dimitrakov J, Anavi A, Mikhailova E, Schachter J. Disseminated Chlamydia trachomatis infection in a newborn. In: Proceedings 4th of the European Society for Chlamydia Research. Helsinky, Finland, August 20-23, 2000, 277.

15. Hollblad-Fadiman K, Goldman SM. American College of Preventive Medicine practice policy statement: Screening for Chlamydia trachomatis. Am J Prev Med 2003; 24; 287-292.

16. Ancel PY, Saurel-Cubizolles MJ, Di Renzo GC, Papiernik E, Breart G. The EUROPOP group social differences of very preterm birth in Europe: interaction with obstetric history. Am J Epidemiol 1999; 149; 908-915.

17. Nyári T, Woodward M, Mészáros G, Karsai J, Kovács L. Chlamydia trachomatis infection and the risk of perinatal mortality in Hungary. $\mathrm{J}$ Perinat Med 2001; 29; 55-59.

18. Nyári T, Woodward M, Kovács L. Should all sexually active young women in Hungary be screened for Chlamydia trachomatis? Eur J Obstet Gynecol Reprod Biol 2003; 106; 55-59.

Received June 1, 2011. Accepted September 21, 2011. 